\title{
Assessment of the Therapeutic Evolution of Psychiatric Patients through Rorschach Psychodiagnosis
}

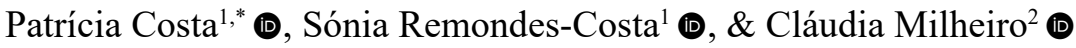 \\ ${ }^{1}$ Universidade de Trás-os-Montes e Alto Douro, Vila Real, Portugal \\ ${ }^{2}$ Hospital de Magalhães Lemos, Porto, Portugal
}

\begin{abstract}
The present work aims to constitute an important contribution to the scientific proof of the effectiveness of psychiatric and psychotherapeutic interventions, through the Rorschach test. A clinical sample of 10 psychiatric patients, admitted and followed at the Day Hospital of a psychiatric hospital in the North of Portugal, where the psychoanalytic orientation intervention model is followed. The data were collected in two moments: upon admission, a sociodemographic and clinical questionnaire and Rorschach's projective proof were applied; after three months of treatment, Rorschach was re-applied, followed by a survey of exclusion criteria and patient evaluation on the therapeutic program. The comparative analysis of the data showed a slight therapeutic evolution and personality functioning.
\end{abstract}

KEYWORDS: therapeutic evolution, psychiatric diagnosis, Rorschach

\section{Avaliação da Evolução Terapêutica de Doentes Psiquiátricos através do Psicodiagnóstico de Rorschach}

\begin{abstract}
RESUMO - O presente trabalho objetiva constituir um contributo de relevo para a comprovação científica da eficácia das intervenções psiquiátricas e psicoterapêuticas, através do teste de Rorschach.Participou no estudo uma amostra clínica de 10 doentes psiquiátricos, admitidos e seguidos no Hospital de Dia de um hospital psiquiátrico da zona norte de Portugal, onde é seguido o modelo de intervenção de orientação psicanalítica. Os dados foram recolhidos em dois momentos: aquando da admissão, tendo sido aplicados um questionário sociodemográfico e clínico e a prova projetiva de Rorschach;após três meses de tratamento, procedeu-se à nova aplicação do Rorschach, seguida de um questionário de despiste de critérios de exclusão e avaliação do doente sobre o programa terapêutico.A análise comparativa dos dados permitiu constatar uma ligeira evolução terapêutica e do funcionamento da personalidade.
\end{abstract}

PALAVRAS-CHAVE: evolução terapêutica, diagnóstico psiquiátrico, Rorschach

Mental disorder is "a syndrome characterized by clinically significant disturbance of the subject's cognition, regulation of emotion, or behavior that reflects a dysfunction of the psychological, biological, or developmental processes underlying mental functioning" (American Psychiatric Association, 2014, p. 20). It is a pathological situation in which disturbances occur in mental organisation, leading to a state of imbalance between the environment and the biological, psychological and sociocultural systems, resulting in an inability to perform the individual's social roles (family, work and community). Thus, according to Sequeira (2006), it results from a conflicting relationship between the individual and the organised society, because there is a very strong difference between both or a predisposition of the individual towards illness, resulting in an alteration in the individual's integration, adaptation and autonomy.

Mental disorder is not considered when the response to a common stressor or loss is expectable or culturally approved, and only if there is dysfunction of the individual can one consider mental disorder, a socially deviant behaviour (e.g. political, religious, or sexual) or a primary conflict between the individual and society (American Psychiatric Association, 2014).

\footnotetext{
* E-mail: psi.patriciacosta@gmail.com

- Submetido: 06/11/2017; Aceito: 09/12/2020.
} 
The clinical profile of patients with mental disorders highlights that the first diagnosis is usually made during adolescence, a period characterised by body changes, mainly related to sexual development, personality consolidation and social transformations, which include a moment of internal preparation for adulthood. At this stage, an identity crisis may occur, which is considered normal, but it may interfere with the onset of a mental disorder in adulthood if it is not timely and properly managed (Oliveira \& Laus, 2011; Silva et al., 2015). Patel and Kleinman (2003) add that factors such as insecurity, despair, rapid social changes, risk of violence and physical illnesses may explain the increased vulnerability for mental illness. In addition, Costa and Ludermir (2005) argue that significant life events act as stressors by causing changes in the endocrine system, making the development of diseases, including mental disorders, more vulnerable.

The existing knowledge about the factors associated with mental and behavioral disorders allows the adoption of measures to reduce morbidity and the impact caused by these pathologies. However, the existence of stigma destroys the confidence that these disorders can be treated, deprives people of their dignity and conditions their participation in society (Alonso et al., 2008). It is strongly associated with mental disorders worldwide, it damages the self-esteem of sick people and conditions their therapeutic adherence and consequent recovery (Watson et al., 2007).

In turn, psychoanalytical models offer clinical psychology a specificity in looking and listening to the dimensions of the subject that it seeks to capture, the latter becoming "captureable" through language (narrativity), the relationship and intersubjectivity (Oneto et al., 2009; Teixeira \& Marques, 2009). The psychodiagnosis is the first step to be taken and the therapeutic attitudes to be followed depend on it (Souza \& Resende, 2012). Therefore, the Rorschach emerges as a privileged instrument in psychological assessment, which allows mediating the access to the subject's internal reality and describes the subject's mental functioning. It is a complex perceptual and projective method that provides the assimilation between stimuli and intrapsychic sensation complexes, investigating healthy and compromised aspects of the personality (Teixeira \& Marques, 2009).

In a space and time established within a relational continent, the subject is invited to give personal meaning to the ten Rorschach cards, whose latent symbolic appeals to different dimensions of himself, producing a narrative that gives an account of the nature of the communication established between intern and the qualities and characteristics of the subject's subjectivity. Thus, we take the Rorschach spots as an object in the psychoanalytic sense of the term, an element of external reality that has psychic qualities that make it apt to be invested, designated, and known. This encounter creates a tension, a catastrophic situation, which forces the subject to a psychic change to regulate the balance, achieved by assigning new meanings through new continent-content relationships (Godinho et al., 2009). The subject thus experiences a catastrophic change: through projective identification, it impregnates its subjectivity in the stain, transforms chaos and its infinite potential, and communicates, in the form of a symbol, a new object (Marques \& Aleixo, 1994). Through the interpretation of the Rorschach response process, it becomes possible to analyze the way the subject uses and communicates his thinking, thus being able to foresee and understand the essence of the subject (Marques, 1996a). In such a way, the global apprehension of the individual becomes possible, encompassing his latent and manifest resources, as well as the aspects of greater vulnerability, giving rise to psychological counseling, a therapeutic indication and an evolutionary prognosis (Chabert, 1998).

Any interpretation of a Rorschach stain implies two moments/movements, which can only be considered as separate for expository purposes: the first one is related to the figure-background differentiation, through the creation of a perceptual continent that highlights part or all of the stain (apprehension mode); the second moment refers to the establishment of a continent-content relationship with the stain, which enables the creation of a new object through the communication and recreation between the internal world and the external reality (Teixeira \& Marques, 2009). The possibility of highlighting the figure on the white background is one of the indicators of a well constituted identity, sufficiently well delimited in relation to the other objects. The white background, as an unremembered memory of an archaic state of benign fusion with the mother that made separation and individuation possible, allows the figure, the object, to stand out, making it apt for relation, transformation and growth. In fact, the colour white contains in itself all colours, which leads us back to questions of origin, infinity and potential.The white background may, then, constitute itself as the base where objects may organise themselves, emerge and create. However, if the presence of the background of primary identification presents gaps, the white can exert a strong power of attraction, constituting a regressive movement towards "nothing “, towards emptiness (Marques, 1996b). In turn, the figure (stain) presents an unknown and destructuring character, which leads us to propose chaos as the psychic quality that defines it. Its symmetrical structure presents cohesion (integration) and the double (dispersion) as psychic qualities. These elements are fundamental in the organisation of psychic life and of the symbolic transformation, mobilising the subject to the establishment of new continent-content relations, in order to order, integrate, signify and communicate his/her experience in the form of a symbol (Marques, 2001).

As Chabert (1998) clarifies, the Rorschach is not studied as a test, but rather in the way it accesses mental functioning according to a psychoanalytic model. Thus, the projective situation consists of an encounter between a subject and the clinician, which is mediated by a paradoxical 
and conflictual material and instruction. Such a situation, the approach of this "object", leads to the emergence of affects/emotions and mobilises unconscious relational movements (Marques, 2001). Once one has access to both conscious and unconscious personality characteristics, there is an opportunity to obtain relevant information about the structure and dynamics of the personality of individuals. In this way, a global understanding of the individual becomes possible, encompassing his latent and manifest resources, as well as the aspects of greater vulnerability, giving rise to psychological counselling, therapeutic indication and evolutionary prognosis (Chabert, 1998).

As a result of the action of the various defence mechanisms, behaviour can take on configurations considered as more or less pathological, more or less mature, or more or less adaptive. There is a clear hierarchisation of defences in relation to their overall adaptability: low-level defences are usually less adaptive, whereas higher-level defences are the most adaptive (Hersoug et al., 2002). Published studies indicate strong evidence that the adaptability of defensive style is correlated with mental health and that some diagnoses are related to specific defence patterns (Bond, 2004). Thus, an important and complex concept such as defence mechanisms covers both the idea of normality and pathology, since a person does not become ill because he or she has defences, but rather because of the ineffectiveness of these defences or their inadequate use.

As change occurs in the psychotherapeutic process, it is then expected that the configuration of defences used by the patient will also change (Bond, 2004). The various psychotherapeutic orientations appeal to the fact that the remission of symptoms only translates into successful treatment if accompanied by changes in the mental structures and unconscious states of the subject (Blatt \&
Auerbach, 2003). For this reason, the authors argue that change in psychotherapy should not only focus on reducing symptomatology, but rather on the structure and content of mental representations, since focus only on symptom reduction reveals little about therapeutic change. Although defence patterns show some resistance to change, despite small or moderate changes, these will reflect a greater capacity to tolerate internal and external stressors and the vicissitudes of life (Hersoug et al., 2002).

With the purpose of comparatively assessing the psychiatric symptoms of patients admitted to a Day Hospital at admission and discharge, Neves (2010) found that the joint use of psychiatric treatment and psychological follow-up is partially effective, particularly in reducing depression. Although no significant differences were found between the moments of admission and discharge in terms of psychiatric symptoms, the study showed that most patients had acquired skills in several areas of their lives for an adequate reintegration into their daily lives. In the same line of research, with a view to monitoring the results of the therapeutic and psychosocial support programme in Day Hospitals and assessing its effectiveness in terms of quality of life and psychopathology, Fonseca (2011) suggested that the therapeutic and psychosocial support programme contributes to improving inpatients' quality of life and psychopathology. However, he admits the existence of factors that may influence its effectiveness, which have not been explored, identified or measured, namely the socio-economic level, the support received, resilience, and the occurrence of positive events, among others.

This study aims to evaluate the therapeutic efficacy of joint psychiatric and psychotherapeutic interventions (individual and group), through the Rorschachpsychodiagnostic test, in view of the scarcity of clinical studies using projective evidence.

\section{METHOD}

\section{Participants}

\section{Sociodemographic Characterization}

Of the initial 21 clinical cases, 11 patients were eliminated due to the exclusion criteria: one clinical case was due to the patient's lack of cooperation in the first moment of evaluation, i.e. upon admission; four clinical cases were eliminated because they had left the hospital before the intervention plan, and the second moment of evaluation, called "abandonment", was not performed; one clinical case was due to a significant life event, i.e. the death of a relative; and five clinical cases were eliminated because they were still under treatment. Thus, a convenience clinical sample composed of 10 psychiatric patients admitted and followedup in the Day Hospital Unit of a psychiatric hospital in the Northern area of Portugal, where the psychoanalytically- oriented intervention model is followed, participated in the study. Regarding gender, eight were female $(80.0 \%)$ and two were male $(20.0 \%)$. The age range varied between 31 and 46 years $(M=39.10 ; S D=5.66)$. Regarding marital status, seven patients $(70.0 \%)$ were married or living with a partner, two were single $(20.0 \%)$ and one was divorced or separated $(10.0 \%)$. In terms of education, the majority has higher education $(60.0 \%)$, two have secondary education $(20.0 \%)$ and two have the third cycle $(20.0 \%)$. Regarding the occupational situation, five of the participants are unemployed $(50.0 \%)$ and an equal percentage is on sick leave/medical certificate.

\section{Clinical Characterisation}

As regards the clinical characteristics of the sample under study, personality disorder is the prevalent clinical picture 
of most patients $(70.0 \%)$ - four with boderline disorder $(40.0 \%)$, two with paranoid disorder $(20.0 \%)$ and one with narcissistic disorder (10.0\%). Three (30.0\%) presented major depressive disorder. As regards comorbid non-psychiatric pathologies, two subjects $(20.0 \%)$ stated their existence. The majority $(80.0 \%)$ assumed not to have any. The clinical disease found was arterial hypertension (20.0\%). Regarding the psychiatric clinical history, the age of the first contact with the mental health services ranged between 15 and 44 years of age ( $M=25.90 ; S D=10.33)$. Of the six subjects with recurrence to full hospitalizations $(60.0 \%)$, their number ranged between one and twelve, composing a mean of three hospitalizations $(S D=4.27)$. Two $(20.0 \%)$ had a previous partial hospitalization. The time of daily use of psychotropic drugs ranged between 4 months and 22 years $(M=111.30$; $S D=111.14)$.

\section{Material}

Data were collected in two moments of evaluation. During the first week of hospitalization, a sociodemographic questionnaire was applied to obtain information on gender, age, marital status, education and occupational situation, and clinical information on the psychiatric history, including clinical diagnosis, non-psychiatric comorbidities, age of first contact with the mental health services, whether or not there was a recurrence of full and/or partial hospitalization and time of daily use of psychotropic drugs.

Finally, the Rorschach projective test was administered, created and developed by the Swiss psychiatrist Hermann Rorschach (Cunha, 2000). This test includes ten cards, each of which embodies an ink stain, ambiguous as to its content and manifest meaning, and contains sensory impressions without a precise semantic meaning. In this sense, each of the Rorschach cards, by appearing as stimulus with objective characteristics, despite its apparently unstructured character, invokes the need for thought organization, from the moment the instruction "Tell me what you imagine from these cards" is given (Chabert, 1998, p. 30).

The second moment of data collection took place three months later, which was the time defined by the therapeutic team for re-evaluation, with the purpose of determining whether the patients should continue to be hospitalized or not. At this second moment, the Rorschach was applied again, as well as a questionnaire to identify exclusion criteria and the patient's assessment of the therapeutic program, with the intention of excluding those who did not adhere to the therapeutic program (with three unjustified absences), did not cooperate in the psychological assessment, suffered a significant life event (death, divorce, unemployment, among others) and were discharged, whether by transfer (worsening of the clinical picture), abandonment or against the opinion of the team.

\section{Procedure}

After permission was granted by the Board of Directors of the Magalhães Lemos Hospital, the participants signed the informed consent according to the Helsinki protocol. Since the Rorschach test was already part of the psychological assessment tools used at the Day Hospital Functional Unit, it was only necessary to spend more time during the psychological observation to answer the questionnaire on sociodemographic and clinical data, the questionnaire on exclusion criteria and the patient's assessment of the therapeutic programme.

Since this was a longitudinal study, data were collected as participants were admitted to partial hospitalisation and discharged. The information about the clinical diagnoses was obtained through the consultation of the medical-psychiatric files.

The Rorschach protocols were rated by two judges, based on the interpretative matrix of the French School, limited to the contributions of Chabert $(1998,2000)$, taken up by some formulations of Marques (2001). As far as some of the quotation parameters are concerned, the referential sustained by Beizmann (1966) served as an anchor in terms of consideration and quotation concerning the quality of the forms inherent to the answers. In concomitance, the statistical standards which guided all comparisons, formulations and interpretations arising from the quantitative data resulted from the confrontation of several authors, proposed by Marques (2001), considering the absence of statistical values referring to the Portuguese population.

\section{RESULTS}

\section{Ist Research Moment:When Patients are Admitted to Day Hospital}

\section{(a) Cognitive Dynamics}

When we associate the high number of global answers $(34.4 \%)$ and the low number of answers with great detail $(58.2 \%)$, we found that these subjects seem to have a predominance of condensed thinking, indicating an excess of generalization of facts or situations. Furthermore, the fact that they did not seek the minutia of detail $(2.7 \%)$ reveals a lack of exploration of the environment surrounding them. The presence of white detail interpretation answers $(4.7 \%)$ may reveal affective deficiencies or even feelings of abandonment, emptiness and lack. The number of human movement responses is within the average range expected (2.5). These interpretations are considered to be signs of internal and reflected control of the manifested activity, of 
a principle of stabilization of affect and motility linked to a process of interiorization.

In relation to the formal quality, the percentage of answers with formal determinants within the average expected interval $(66.6 \%)$ in detriment of the low number of answers of good formal quality (64.9\%) reveal that, in the approximation to reality, rational and socialized thinking is privileged in an objective attitude with reality, despite this being unsatisfactory, thus disclosing failures in the socializing insertion in the real.

\section{(b) Affective Dynamics}

The analysis of the results in Table 1 shows that there are no conflicts regarding affective experiences, with the results obtained in the Type of Intimate Resonance (IRT) and in the Latent Trends (TL) characterizing the affective experiences of the participants as introversive, pointing out a tendency to be concerned with their own ideas and thoughts, more oriented towards inner life, with disinterest in external events.

Table 2 systematizes the data referring to the indicators of affective control. There was a predominance of color responses associated with formal imprecision (inadequate) indicating a marked difficulty in maintaining an adequate coordination of emotional experiences according to their intensity, due to the immaturity of the internal resources of containment, emotional instability and difficulty in postponing impulsive discharges $(\mathrm{FC}<\mathrm{C}+\mathrm{CF})$ and impairment in the ability to use reason efficiently to dominate distress and depression $(\mathrm{FE}<\mathrm{E}+\mathrm{EF})$. In spite of that, a predominance of the great kinesthesias is noted, in accordance with what is expected for adults, pointing to a good potential for internal dynamism $(\mathrm{K}>\mathrm{k})$.

\section{(c) Socialization Dynamics}

Although the banal answers are indicative of a good socialization and adaptation to the environment, the revealed presence of a high number of banalities (30.4\%) may operate as a defence mechanism, referring to a surface socialization. As regards contents, the number of animal representations within the average expected interval (48.6\%) may suggest a defensive attitude towards the stimulus, a defence to avoid authentic contact and true relationships. However, the high use of answers with human content (20.4\%) signals the aptitude to recognize one's own subjective identity and points to the capacity to establish contacts with others.

\section{2nd Research Moment:After Treatment/ Therapeutic Evolution of Patients in Day Hospital}

\section{(a) Cognitive Dynamics}

The cognitive-perceptive strategies used through the modes of apprehension within the average expected interval show a concern to delimit percepts well, by the tendency to privilege the global mode of apprehension $(28.2 \%)$, but where great details $(61.7 \%)$ are also invested. A greater desire to live is thus revealed. But the fact that they hardly seek the minutia of detail (5.8\%) also reveals a lack of exploration of the environment surrounding them. The presence of answers interpreting white detail $(4.1 \%)$ is suggestive of affective needs or even feelings of abandonment, emptiness and lack. In this context, given the number of answers and the creativity emanating from the answers of human movement within the average expected interval (2.3), the intellectual activity of the subjects does not seem to be inhibited or restrained.

When taking into consideration the formal quality, it can be seen that the percentage of answers with formal determinants is close to the lower threshold of the expected average interval $(61.9 \%)$. Thus, there may be a certain complementarity between the use of the formal and the intellectual on the one hand, and subjectivity and emotion on the other. As for the number of answers with good formal

Table 1

Frequency of Indicators Obtained by the Rorschach Regarding Affective Dynamics at the Time of Admission of Patients to Day Hospital

\begin{tabular}{lcccc}
\hline Variables & Introversive & Extratensive & Ambigual & Restricted \\
\hline TRI & $5 \uparrow$ & 4 & 1 & 0 \\
TL & $4 \uparrow$ & 3 & 0 & 10 \\
\hline
\end{tabular}

Note. $\mathrm{TRI}=$ Intimate resonance type; $\mathrm{TL}=$ Latent tendencies.

Table 2

Frequency of Indicators Obtained by the Rorschach Regarding Affective Control at the Time of Admission of Patients to Day Hospital

\begin{tabular}{lcccc}
\hline Variables & Adequate & Inadequate & N \\
\hline FC:C+CF & 4 & $6 \uparrow$ & $6 \uparrow$ & 10 \\
FE: + FE & 4 & 2 & 10 \\
K: $\mathrm{k}$ & $8 \uparrow$ & 10 & \\
\hline
\end{tabular}


quality, we noticed a value much lower than expected (64.5\%), suggesting that participants make a less rigorous approach to reality, which may contaminate the quality of their thinking and the way they interpret the objective and relational reality.

\section{(b) Affective Dynamics}

The analysis of the results in Table 3 allows us to observe the existence of conflicts regarding affective experiences. The results obtained in the TRI define the participants' affective experiences as extratensive. Subjects with this type of resonance are characterised by their impulsiveness and excitability, whose use is often inappropriate. The secondary formula is of the introversive type, varying in the opposite direction of the TRI. Thus, if the participants' apparent relationship with the external world seems to be dominated by extroversion, impulsivity and irritability, their internal tendency seems to be dominated by greater inhibition and introversion.

Table 4 systematises the data concerning the indicators of affective control. A predominance of colour responses associated with formal imprecision (inadequate) was observed, which means that subjects may have some difficulty in controlling their affections, revealing weaknesses in the formal reference and defence mechanisms to affections $(\mathrm{FC}<\mathrm{C}+\mathrm{CF})$ and impairment in the ability to use reason efficiently to control distress and depression ( $\mathrm{FE}>\mathrm{E}+\mathrm{EF})$. On the other hand, a predominance of the major kinaesthesias indicates a good potential for internal dynamism $(\mathrm{K}>\mathrm{k})$.

\section{(b) Socialisation Dynamics}

As for socializing on the surface, it was found that the participants have a high number of responses of animal content $(52.8 \%)$, therefore greater immaturity in the process of contact with reality, a more intuitive and less elaborate perception and a stereotype of the thought. Concomitantly, the low use of banal responses $(22.6 \%)$ may show some lack of contact with the objective and social reality, as well as disinterest or systematic opposition from the social environment. with regard to in-depth socialization, the percentage of responses of human content, when situated at the threshold of the expected average range (19.8\%), may refer to the difficulty of the participants in identifying themselves and coming into contact with others, as well as maintaining deeper relationships.

Table 3

Frequency of Indicators Obtained by the Rorschach Regarding Affective Dynamics after Treatment/Therapeutic Evolution of Patients in Day Hospital

\begin{tabular}{lcccc}
\hline Variables & Introversive & Extratensive & Restricted & N \\
\hline TRI & 3 & $7 \uparrow$ & 0 & 10 \\
TL & $6 \uparrow$ & 1 & 3 & 10 \\
\hline
\end{tabular}

Note $. \mathrm{TRI}=$ Intimate resonance type $\mathrm{TL}=$ Latent tendencies

Table 4

Frequency of Indicators Obtained by the Rorschach Regarding Affective Control after Treatment/Therapeutic Evolution of Patients in Day Hospital

\begin{tabular}{lccc}
\hline Variables & Adequate & Inadequate & N \\
\hline FC:C+CF & 4 & $6 \uparrow$ & 10 \\
FE: + FE & 3 & $7 \uparrow$ & 10 \\
K:k & $6 \uparrow$ & 4 & 10 \\
\hline
\end{tabular}

\section{DISCUSSION}

The main objective of this research work was to evaluate the therapeutic efficacy of joint psychiatric and psychotherapeutic interventions (individual and in group), through the Rorschach psychodiagnostic test, thus contributing to the increase in studies using the Rorschach as a clinimetric instrument for the evaluation of personality.

Starting with the results regarding the sociodemographic data of the sample under study, as can be seen, most participants are in adulthood, a period in which the individual is at full maturity, professionally defined and able to associate with other people in a position of equality, at a stage when they are considered quite productive (Oliveira \& Laus, 2011; Silva et al., 2015). In terms of gender, the sample proved to be predominantly female. This finding is in line with several studies conducted in psychiatric services (Catty, Goddard, \& Burns, 2005; Catty, Goddard, White, \& Burns, 2005). However, it differs from others that found a predominance of males (Dalgalarrondo et al., 2003; Melo \& Guimarães, 2005). This situation may be explained by the fact that the Day Hospital does not admit patients with 
alcohol and drug use or abuse disorders, having a decrease in the admission of males, since this disorder predominantly affects male individuals (Bruffaerts et al., 2004). With regard to marital status, most participants were married or living in a consensual union, which was not consistent with the results of previous studies, which indicate that the prevalence of mental disorders is more associated with single individuals (Lima et al., 2014; Silva et al., 2015). Plausible explanations for this data can be made by judging the coexistence with a partner as a significant stress-producing event (Costa \& Ludermir, 2005). However, it is important to make a caveat corresponding to the possibility of reverse causality, in which individuals with mental disorders may have less opportunity to marry. The characteristics of this study preclude analysis. As regards education, most patients in the sample have higher education qualifications. This finding is also not in line with previous scientific evidence, as psychiatric illness compromises the possibilities of life choices, in addition to influencing aspirations, self-esteem and the acquisition of new knowledge. On the contrary, some data point out that higher education may motivate healthier attitudes and behaviors, functioning as a health protector (Ludermir \& Melo Filho, 2002; Patel et al., 1999). As for the occupational situation, half of the participants are unemployed, which shows a possible process of exclusion of patients in the productive sector (Silva et al., 1999). This situation shows that the Day Hospital deals with severe clinical conditions, and even if it is necessary to select the patients, they present inactivity, which causes a decrease in self-esteem, requiring psychosocial rehabilitation.

Within the scope of clinical characterisation, the most common diagnosis was personality disorders, which corresponds to what is expected taking into account that the severity of these disorders predicts a greater need for treatment at a Day Hospital than other pathologies. The patients' first contact with mental health services occurred during adulthood, which may result from an identity crisis that was not timely and properly managed during adolescence, as corroborated by Silva et al. (2015). Most of them reported no previous history of previous hospitalisations in Day Hospitals, only hospitalisations in full regime, which may reflect the fact that this type of service is a more recent alternative in the history of psychiatry. The existence of studies such as this one, in which we try to objectively assess the results, may contribute to the credibility of the interventions and their dissemination among professionals.

As regards the comparative analysis of results in terms of apprehension modes, differences were found in the two moments of research (admission to Day Hospital and three months later). Initially, it was found that patients made the apprehension of percepts predominantly in detail, in spite of the $\mathrm{D} \%$ being below the reference values, indicating lack of interest for the concrete and the real. On the other hand, the mean number of global answers was slightly high, which may reflect a defensive behaviour using a global and adaptive reality against the emergence of representations and/or affections (Chabert, 1998; Oneto et al., 2009). In the second moment of assessment, we noticed a decrease in defensive conduct, with a slight increase in projective capacity, which may be explained by the familiarisation with the testing situation, on the one hand, and, alternatively, by the decrease in the use of defensive mechanisms (normal G\% and $\mathrm{D} \%$ ). White sensitivity remained with relatively stable values at admission and after treatment, although below the normative values, which may indicate a persecutory experience with depressive features (Chabert, 1998).

In terms of formal aspects, no changes were observed throughout the treatment. There is a rate of answers with formal determinants within the normative values, signalling a current apprehension permanently disconnected from fanciful and emotional implications. The formal quality of the answers is clearly below the norms, which may indicate "infiltrations" of an internal reality, through the defensive apparatus, from which subjects defend themselves preferably using external reality (Soares \& Marques, 2009). Despite the clear search for adaptation to reality in both moments of assessment, this is not always achieved, since the internal reality overlaps the external reality $(\mathrm{K} \uparrow)$.

In relation to the type of affective experience, patients showed significantly different behaviours in both moments of research. At admission, a predominance of introversive experience was observed, indicating a functioning that privileges thinking over emotion. Reinforcing these results and the conclusions arising from them, after the treatment/ therapeutic evolution, the introversive dominance enters the secondary formula, characterized by resources of reflexive positioning in front of emotional experiences, not fully developed, for the elaboration of affections. Knowing that this fact conjugated with the TRI (dialectic between emotionality and representation) may dictate the existence of conflicts, each one should point to distinct modes of functioning, as seems to be the case. The existence of subjacent internal conflicts is made evident, bearing in mind that the prevalent TRI will have been the extrantensive one. It is evident that the subjects' inner conflicts will manifest themselves in interaction with the other, this being a positive consequence (still in evolution) of the exit from the more self-centred state which is part of the process of personal growth and therapeutic evolution.

Regarding social contact, patients also showed different procedures at the two moments of evaluation. First of all, the production of human contents slightly above average stands out, revealing an adequate capacity for relationships, as well as the ability to recognize one's subjective identity. After the treatment/therapeutic evolution, the rate of animal contents is slightly elevated, and may indicate stereotypes of thought and social conformity, or serve as a vehicle for the expression of aggressiveness, when in morbid and banal type answers. Noting that there is a trend reversal for $\mathrm{A} \uparrow$ and $\mathrm{H}$ normal 
(the production of contents does not go below the expected average range), and being these more structural and subtle changes that the Rorschach shows and other tests do not, it is inferred that the interventions in Day Hospital are very interpersonal. On the other hand, it is understood that three months is a very short time for a therapeutic process which starts with some disorder to be successful, since structural changes happen very slowly and results are only observed in the long term.

Taking into account the general objective of the present study, the application of the Rorschach projective test at two different moments allowed us to observe a slight therapeutic and personality development. As it is known, personality traits are aspects inherent to the individual's own structure and therefore take more time to change. In relation to these factors, it was not expected that significant change would be observed, given that the beginning of psychotherapy can provoke destabilization and defence patterns show some resistance to change (Hersoug et al., 2002). The fact that the study time of therapeutic evolution was only three months may have been insufficient to verify more profound changes in personality functioning. In a longer period of time, different results would certainly be found. Even so, the choice of this instrument is valid since it is part of the institutional protocol for psychological assessment of patients admitted to the Day Hospital. Given the current Portuguese disinvestment in the scientific production about this instrument and, consequently, the inadvisability of its use in some national universities, this study aimed at exploring the clinimetric properties of the test and contributing to the invitation for future research in the area.

The relevance and originality of this study focuses on the study of the therapeutic evolution in a clinical sample of psychiatric patients in Day Hospital, through the Rorschach psychodiagnostic test, as an important contribution to research designs based on clinical and psychotherapeutic practice. The study has some limitations resulting from several factors. One of the constraints recalls that the initial sample was of 21 patients, but due to exclusion criteria it was reduced to 10 , with a significant sample loss of 11 subjects. Considering the final sample, the small sample size may limit possible generalizations of the results. Another issue which may be considered a limitation is the impossibility of considering external factors to the psychotherapy which may have contributed to the obtainment of the results, due to the inexistence of experimental control conditions. Finally, the consequences that the announcement of the patient's discharge causes in partial hospitalization patients, as one of the anxiogenic and destabilizing factors, should also be considered (Neves, 2010). A feeling of possible "abandonment" is evident, apparently leading to a setback in their evolution, which is visible in their adherence to the therapeutic process, with a certain regression at the time of this announcement.

Finally, it is important to continue the development of studies in this area, particularly longitudinal studies with longer intervals of time between the moments of evaluation (6 months/1 year) or using control groups, as the results, having been suggestive, point to a potential research path.

\section{REFERENCES}

Alonso, J., Buron, A., Bruffaerts, R., He, Y., Posada-Villa, J., Lepine, J. P. .. Von Korff, M. (2008). Association of perceived stigma and mood and anxiety disorders: Results from the World Mental Health Surveys. Acta Psichiatrica Scandinavica, 118(4), 305314. 10.1111/j.1600-0447.2008.01241.x.

American Psychiatric Association (2014). DSM-V: Manual de diagnóstico e estatística de transtornos mentais ( $\left.5^{\mathrm{a}} \mathrm{ed}\right)$. Climepsi Editores.

Beizmann, C. (1966). Livret de cotation des formes dans le Rorschach. Centre de Psychologie Appliquée.

Blatt, S. J., \& Auerbach, J. S. (2003). Psychodynamic measures of therapeutic change. Psychoanalytic Inquiry, 23(2), 268-307. $10.1080 / 07351692309349034$

Bond, M. (2004). Empirical studies of defense style: Relationships with psychopatology and change. Harvard Review of Psychiatry, 12(5), 263-278. 10.1080/10673220490886167

Bruffaerts, R., Sabbe, M., \& Demyttenaere, K. (2004). Effects of patient and health-system characteristics on community tenure of discharged psychiatric inpatients. Psychiatric Services, 55(6), 685-690.10.1176/appi.ps.55.6.685

Catty, J., Goddard, K., \& Burns, T. (2005). Social services and health services day care in mental health: The social networks and care needs of their users. International Journal of Social Psychiatry, 51(1), 23-34.10.1177/0020764005053267

Catty, J., Goddard, K., White, S., \& Burns, T. (2005). Social networks among users of mental health day care: Predictors of social contacts and confiding relationships. Social Psychiatryand Psychiatric Epidemiology, 40(6), 467-474. 10.1007/s00127-005-0909-y

Chabert, C. (1998). O Rorschach na clínica do adulto. Climepsi Editores.

Chabert, C. (2000). A psicopatologia à prova no Rorschach. Climepsi Editores.

Costa, A. G., \& Ludermir, A. B. (2005). Transtornos mentais comuns e apoio social: Estudo em comunidade rural da zona da Mata em Pernambuco, Brasil. Cadernos de Saúde Pública, 21(1), 71-79.10.1590/S0102-311X2005000100009

Cunha, J. A. (2000). Psicodiagnóstico-V (5 ed.). Artmed Editora.

Dalgalarrondo, P., Botega, N. J., \& Banzato, C. E. M. (2003). Pacientes que se beneficiam de internação psiquiátrica em hospital geral. Revista de Saúde Pública, 37(5), 629634.10.1590/S0034-89102003000500013

Fonseca, V. C. R. (2011). Qualidade de vida e psicopatologia intervenção terapêutica em Hospital de Dia [Tese de mestrado, Universidade de Coimbra]. FMUC Medicina - Teses de Mestrado.http://hdl.handle.net/10316/18425

Godinho, M. Q., Marques, M. E., \& Pinheiro, C. B. (2009). A expressão no Rorschach dos fenómenos transitivos e do espaço potencial na personalidade boderline. Análise Psicológica, 27(3), 349-363.http://hdl.handle.net/10400.12/243

Hersoug, A. G., Sexton, H. C., Høglend, P. (2002). Contribution of defensive functioning to the quality of working alliance and 
psychoterapy outcome. American Journal of Psychoterapy, 56(4), 539-554.10.1176/appi.psychotherapy.2002.56.4.539

Lima, L. H. O., Sousa, M. S., Souza Neto, M. J., Oliveira, R. K. C., \& Luz, N. D. (2014). Caracterização clínica e epidemiológica dos usuários do Hospital-Dia. Revista de Enfermagem da UFPI, 3(4), 57-63.https://doi.org/10.26694/reufpi.v3i4.2377

Ludermir, A. B., \& Melo Filho, D. A. (2002). Condições de vida e estrutura ocupacional associadas a transtornos mentais comuns. Revista de Saúde Pública, 36(2), 213-221.10.1590/ S0034-89102002000200014

Marques, M. E. (1996a). Comunicação, interpretação e simbolização no/para o Rorschach. Análise Psicológica, 14(1), 39-44. http:// hdl.handle.net/10400.12/3528

Marques, M. E. (1996b). Feminino, fecundo e finito: Expressões nos Rorschach de adolescentes. Análise Psicológica, 14(1), 45-52.http://hdl.handle.net/10400.12/3529

Marques, M. E. (2001). A psicologia clínica e o Rorschach (2 $2^{\mathrm{a}} \mathrm{ed}$.) Climepsi Editores.

Marques, M. E., \& Aleixo, P. (1994). O Rorschach e a revelação do trabalho de ligação e de transformação do interno e externo. Análise Psicológica, 12(4), 459-462.http://hdl.handle. net $/ 10400.12 / 3055$

Melo, A. P. S., \& Guimarães, M. D. C. (2005). Factors associated with psychiatric treatment dropout in a mental health reference center, Belo Horizonte. Revista Brasileira de Psiquiatria, 27(2), 113-118.10.1590/S1516-44462005000200008

Neves, I. M. S. (2010). A sintomatologia psiquiátrica de utentes em internamento parcial no Hospital de Dia em hospital psiquiátrico: Estudo comparativo entre os momentos de admissão e alta [Tese de mestrado, Universidade Fernando Pessoa]. FCHS (DCPC) - Dissertações de Mestrado. http:// hdl.handle.net/10284/1648

Oliveira, R. P., \& Laus, A. M. (2011). Caracterização de pacientes de unidade de internação psiquiátrica, segundo grau de dependência do cuidado de enfermagem. Revista da Escola de Enfermagem da USP, 45(5), 1164-1170.10.1590/S008062342011000500019

Oneto, M. M., Marques, M. E., \& Pinheiro, C. B. (2009). A natureza e especificidade do espaço mental através do
Rorschach. Um espaço potencial? - Análise de um protocolo de uma paciente limite. Análise Psicológica, 27(3), 331347.10.14417/ap.222

Patel, V., Araya, R., Lima, M., Ludermir, A., Todd, C. (1999). Women, poverty and common mental disorders in four restructuring societies. Social Science \& Medicine, 49, 14611471.10.1016/s0277-9536(99)00208-7

Patel, V., \& Kleinman, A. (2003). Poverty and common mental disorders in developing countries. Bulletin of the World Health Organization, 81(8), 609-615.10.1590/S004296862003000800011

Sequeira, C. (2006). Introdução à prática clínica: Do diagnóstico à intervenção em enfermagem de saúde mental e psiquiátrica. Quarteto Editora.

Silva, J. P. L., Coutinho, E. S. F., \& Amarante, P. D. (1999). Perfil demográfico e sócio-econômico da população de internos dos hospitais psiquiátricos da cidade do Rio de Janeiro. Cadernos de Saúde Pública, 15(3), 505-511.10.1590/S0102311X1999000300007

Silva, T. L., Maftum, M. A., Kalinke, L. P., Mathias, T. A. F., Ferreira, A. C. Z., Capistrano, F. C. (2015). Perfil sociodemográfico e clínico dos pacientes em tratamento na unidade psiquiátrica de um hospital geral. Cogitare Enfermagem, 20(1), 112120.10.5380/ce.v20il.36414

Soares, A. S., \& Marques, M. E. (2009). Crescer por dentro - A barreira de contacto no processo adolescente através do Rorschach. Análise Psicológica, 27(3), 259-267. 10.14417/ ap. 209

Souza, C. C., \& Resende, A. C. (2012). Transtornos psicológicos em adolescentes socioeducandos. Avaliação Psicológica, 11(1), 95-109.http://pepsic.bvsalud.org/scielo.php?script=sci arttex t\&pid $=$ S1677-04712012000100010

Teixeira, V., \& Marques, M. E. (2009). O buraco negro na patologia limite: Um contributo da/para a técnica Rorschach. Análise Psicológica, 28(3), 281-293.http://hdl.handle. net/10400.12/240

Watson, A. C., Corrigan, P., Larson, J. E., \& Sells, M. (2007). Selfstigma in people with mental illness. Schizophrenia Bulletin, 33(6), 1312-1318.10.1093/schbul/sbl076 